\title{
Application of Structural Equation Modeling (SEM) in Estimating the Contributing Factors to Satisfaction of TASKA Services in East Coast Malaysia
}

\author{
Azrul Fazwan Kharuddin ${ }^{\text {* }}$, Norazura Azid ${ }^{2}$, Zaida Mustafa ${ }^{3}$, \\ Ku Faridah Ku Ibrahim ${ }^{3}$, Darvinatasya Kharuddin ${ }^{4}$ \\ ${ }^{1}$ Graduate School of Business, Universiti Tun Abdul Razak, Malaysia \\ ${ }^{2}$ SMK Jeram, Selangor, Malaysia \\ ${ }^{3}$ School of Education \& Humanities, Universiti Tun Abdul Razak, Malaysia \\ ${ }^{4}$ School of Mathematics, Universiti Sains Malaysia, P.Pinang, Malaysia \\ *Corresponding email: azrulfazwan@unirazak.edu.my
}

Received: 06 August 2019; Accepted: 04 April 2020; Published: 13 May 2020

To cite this article (APA): Kharuddin, A. F., Azid, N., Mustafa, Z., Ku Ibrahim, K. F., \& Kharuddin, D. (2020). Application of Structural Equation Modeling (SEM) in Estimating the Contributing Factors to Satisfaction of TASKA Services in East Coast Malaysia. Asian Journal of Assessment in Teaching and Learning, 10(1), 69-77. https://doi.org/10.37134/ajatel.vol10.1.8.2020

To link to this article: https://doi.org/10.37134/ajatel.vol10.1.8.2020

\begin{abstract}
This research shows the application of the Structured Equation Modeling (SEM) to obtain the best model for studying the relationship between the more efficient and accurate against the findings and the interpretation of the variables. The objectives of the study are to assess the reliability of the developed instrument and to test construct validity of the research instruments in estimating the contributing factors to TASKA service satisfaction. The proportionate stratified random sampling method was used to select a total of 61 TASKAs from three states on the east coast of Malaysia consisting of 273 parents and guardians which are currently using the TASKA services. Validity and reliability of the measurement model in the analysis using Structural Equation Modeling (SEM) method. Measurement models were data-based and fit based on the fit index (CMF) $\chi 2=3230.541$, with degrees of freedom $(\mathrm{df})=902, \mathrm{CMIN} / \mathrm{df}=3.582(\leq 5.0), \mathrm{CFI} \& \mathrm{TLI}(\leq 0.9)$, and RMSEA $=0.070(\leq 0.1)$. Based on the results obtained, all indices meet standardized metric and assessment tools have proven to be a good instrument. The results show that there are 5 factors that influence parents' satisfaction with the quality of services offered by TASKA. Analysis found that the combination of manage, grow, fees, activity and cost constitutes a strong association to estimate a complete structured equation model while supported by demographic factors such as education level, occupation, location, distance, agency, status and age of children to strengthen the TASKA selection factor. Research shows that this TASKA service model can assist as a guide in improving the existing quality for future improvement. Furthermore, it can be used as a module in providing the best quality of services to the satisfaction of parents and guardians.
\end{abstract}

Keywords: Structural Equation Modeling, Measurement Model, Goodness of fit index, Validity and Reliability

\section{INTRODUCTION}

The quality of education has historically been defined as an industry that is influenced by two significant interconnected inputs namely wealth and socioeconomic status (SES). Significant conclusions, even to the most casual observers, good-performing schools will be the top choice and poor-performing schools will be the last option (Cava-Tadik et al., 2020). Human resource management in education essentially is concerned with three major issues namely assessing the need for staff, satisfying the need for staff and maintaining and improving the staff services.

Functions of Human Resources Management in Education is a set of practices and methods of integrating and maintaining the teaching staff in the school so that the school can achieve their purpose and as well as meet the goals for which they were established (Silver et al., 2017). The particular attention 
of educational path is about academic, literature and success management (Papadaki et al., 2019).

This study examines the empirical evidence surrounding service quality satisfaction. The focuses on the factors that influence service quality satisfaction, including management system, fees, cost allocation, kids grow and activities. Outcome factors, at the organisational and individual level, are also explored (Scheiner et al., 2016).

The role of the caregiver or childcare worker is very important in providing high quality childcare in the development of future leaders. For the next generation to grow, childcare centers need to enhance and stimulate quality assurance practices among staff. The purpose of this study was to validate the factors that influence parent's satisfaction towards quality services (management system, fees, cost allocation, kids grow and activities) provided by TASKA in three states on the east coast of Malaysia. Precisely, the objectives of the study are to assess he reliability of the developed instrument and to test construct validity of the research instruments. Random sampling techniques were used to select respondents from registered childcare centers in Pahang, Kelantan and Terengganu.

\section{MATERIALS AND METHODOLOGY}

Structural equation modeling (SEM) is a prevailing, multivariate technique found increasingly in scientific investigations to experiment and assess multivariate causal associations (Briere et al., 2017). The popularity of this approach is increasing among researchers, academics and students. This is due to the flexibility and coverage in producing accurate and fast estimates in making predictions (Jacobucci et al., 2017). Steps in the SEM analysis follow model specifications, data collection, budgeting, interpretation and modification of the model (Godbout et al., 2019). However, the validity of this index value must be obtained to assure the acceptance and rejection of the model (Garn \& Webster, 2018). This acquisition is used in the assessment to improve the facilities offered at early childcare center called TASKA throughout the east coast of Malaysia. The data obtained from this survey estimate the major contributing factor to consumer satisfaction from parents and guardian's eyesight.

\section{Subjects}

Samples of 273 parents/ guardians from various TASKA at the east coast of Malaysia (Pahang, Terengganu and Kelantan) were taken to fit the model in this study. The respondents of the survey were individuals who received the TASKA service directly with the various facilities offered. Identified mediating variables are including the services provided, aspects of parenting, management system, fees, activities, kids grow and cost. All of these determinants are assessed to be the level of consumer satisfaction through parent/guardian perspectives. These different perspectives act as the intermediary variables that are keys of success to this study. The data were obtained from a survey conducted through a questionnaire that has been verified for its reliability. The stratified random sampling method is used to proportionate population values. IBM SPSS ${ }^{\circledR}$ AMOS ${ }^{\circ}$ v 23.0 software has been used for model fitting and analysis purposes. The analysis used in this study was Confirmatory Factor Analysis (CFA), Discriminant Validity (DV), Path Analysis (PA) and Structured Equation Modeling (SEM).

The first step is to carry out the Confirmatory Factor Analysis (CFA) that is commonly used in social investigations. It is an advanced analysis of the Exploratory Factor Analysis (EFA) and is used to test whether the steps are in line with the investigators' objective or need to be justified. Therefore, the objective of the CFA is to rectify the data corresponds to the hypothesized measurement model. Model fit measures are then obtained to assess the extent to which the proposed model has a covariance that links all items in the model.

\section{Data Analysis}

The goodness-of-fit index was verified by $\chi^{2}$ values (degree of freedom or df, p-value), weighted root mean square residuals (WRMR; reference value: $\leq 1.0$ ), the Tucker-Lewis index (TLI; reference value: $\geq$ 0.9 ), the comparative fit index (CFI; reference value: $\geq 0.9$ ), and the root mean square error of approximation (RMSEA; reference value: $\leq 0.05$ ). The convergent validity of the factor construct was 
based on the following criteria: standardized regression coefficients of observed variables $\geq 0.50$, construct reliability $(\mathrm{CR}) \geq 0.7$, and average variance extracted $(\mathrm{AVE}) \geq 0.5$. The discriminant validity of the factors estimated by CFA is confirmed if the inter-factor correlation coefficients are $\leq 0.80$ and the AVE of latent variables is greater than the square of correlation coefficients of the latent variables. To assess the criterion validity of the TASKA service quality, a standard scale with proven validity and reliability was essential. However, because there are very few instruments designed to measure service quality conceding and almost none have proven validity and reliability, the findings from this study were compared to a previous study (Rentzou, 2017) on the quality of early childhood classroom environments. Hence, the Pearson's correlation coefficient between the TASKA service quality and mediators were obtained for criterion validity. To enumerate internal consistency, Cronbach's alpha correlation coefficient was obtained.

\section{Convergence validity}

Several techniques were used to assess the reliability coefficient, Cronbach alpha, $\alpha(1951)$, and to assess face, construct and convergence validity. In order to ascertain face validity, an initial questionnaire was passed through routine editing after it was given to the panel of experts consisting 6 experts in early childhood education. They were asked to respond to the questionnaire and very few comments in fact were received and some minor changes were done to enhance the clarity. Confirmatory factor analysis (CFA) is the method for measuring latent variables (Hoyle 1995; 2011; Kline 2010; Byrne 2013). It excerpts the latent construct from other variables and recompenses the most variance with related variables. For example, management factor as a latent variable is measured by the observation of cleanliness activity (i.e., physical environment, children sensitivity to TASKA and physical hygiene, (Berti et al., 2019). Confirmatory factor analysis evaluates latent variables based on the associated variations of the dataset (e.g., association, causal association) and can reduce the data dimensions, standardize the scale of multiple indicators, and account for the associations' integral in the dataset (Byrne, 2013).

Therefore, to hypothesize a latent variable, one should be distressed about the reason to use a latent variable. In the management factor example given above, physical environment and children sensitivity are latent variables that account for the association in the dataset. Shao et al. (2015) applied CFA to compress the cleanliness activity features to one variable that accounted for physical environment, children sensitivity to TASKA and physical hygiene. Also, Capmouteres and Anand (2016) defined the Confirmatory factor analysis (CFA) is a tool that is used to approve or discard the measurement theory. In addition to CFA, there is another type of factor analysis: exploratory factor analysis (EFA). The statistical estimation technique is the same for both. The CFA is applied when the indicators for each latent variable is specified according to the related theories or prior knowledge (Austin et al., 2020), whereas EFA is applied to find the fundamental latent variables. In practice, EFA is often performed to select the useful underlying latent constructs for CFA when there is little prior knowledge about the latent construct (Hajizadeh \& Zali, 2016). Confirmatory factor analysis (CFA) was used to quantify the items' construct validity in each sub construct that measure TASKA service quality Instrument. The first step in this measurement model is to determine the convergent validity and discriminant validity. Table 1 shows the result of CFA for measurement model, the factor loading of more than 0.70 , Average variance extracted (AVE) more than 0.50 and Composite reliability (CR) more than 0.70 , thus this TASKA service quality instrument has good convergent validity and adequate reliability.

\section{Discriminant validity}

There are several types of validity measures that include face validity and construct validity. Mohajan (2017) proposed two types of validity: convergent and discriminating validity. Convergent validity is measured by average variance extracted for each construct during the reliability analysis that should be 0.5 or $50 \%$ or better. Table 1 show the reliability values for the various construct with variance extracted in diagonal format given in bold. Cronbach alpha for the construct range from 0.78 to 0.89 indicating a sufficient level of reliability and convergent validity of all constructs. In general, results show in Table 2 that both validities are satisfied. 
Application of Structural Equation Modeling (SEM) in Estimating the Contributing Factors to Satisfaction of TASKA Services in East Coast Malaysia

Table 1. Result of CFA for measurement model

\begin{tabular}{|c|c|c|c|c|}
\hline \multirow[b]{2}{*}{ Construct } & \multirow[b]{2}{*}{ Item } & \multicolumn{3}{|c|}{ Convergence validity } \\
\hline & & Factor Loading & $\begin{array}{c}\text { Composite } \\
\text { reliability }(>0.7)\end{array}$ & $\begin{array}{l}\text { Average variance } \\
\text { extracted }(>0.5)\end{array}$ \\
\hline Demographic factor & $\begin{array}{c}\text { EduF } \\
\text { EduM } \\
\text { EduG } \\
\text { OccF } \\
\text { OccM } \\
\text { Distance } \\
\text { Location } \\
\text { Agency } \\
\text { Status } \\
\text { Kid Age1 } \\
\text { Kid Age2 } \\
\end{array}$ & $\begin{array}{l}0.852 \\
0.896 \\
0.715 \\
0.747 \\
0.887 \\
0.784 \\
0.821 \\
0.808 \\
0.844 \\
0.830 \\
0.729 \\
\end{array}$ & 0.881 & 0.772 \\
\hline Manage & $\begin{array}{l}\text { M1 } \\
\text { M2 } \\
\text { M3 }\end{array}$ & $\begin{array}{l}0.884 \\
0.871 \\
0.793\end{array}$ & 0.786 & 0.682 \\
\hline Fees & $\begin{array}{l}\text { F1 } \\
\text { F2 } \\
\text { F3 } \\
\text { F4 } \\
\text { F5 } \\
\end{array}$ & $\begin{array}{l}0.889 \\
0.883 \\
0.906 \\
0.934 \\
0.931 \\
\end{array}$ & 0.893 & 0.705 \\
\hline Cost & $\begin{array}{l}\mathrm{C} 1 \\
\mathrm{C} 2 \\
\mathrm{C} 4 \\
\mathrm{C} 5\end{array}$ & $\begin{array}{l}0.986 \\
0.984 \\
0.949 \\
0.982\end{array}$ & 0.807 & 0.871 \\
\hline Activity & $\begin{array}{l}\text { A1 } \\
\text { A2 } \\
\text { A3 } \\
\text { A4 } \\
\text { A5 } \\
\text { A6 }\end{array}$ & $\begin{array}{l}0.897 \\
0.902 \\
0.909 \\
0.873 \\
0.904 \\
0.889\end{array}$ & 0.910 & 0.822 \\
\hline Grow & $\begin{array}{l}\text { G1 } \\
\text { G2 } \\
\text { G3 } \\
\end{array}$ & $\begin{array}{l}0.816 \\
0.834 \\
0.831 \\
\end{array}$ & 0.883 & 0.698 \\
\hline Satisfaction & $\begin{array}{l}\text { S1 } \\
\text { S2 } \\
\text { S3 } \\
\text { S4 } \\
\text { S5 } \\
\text { S6 }\end{array}$ & $\begin{array}{l}0.747 \\
0.831 \\
0.784 \\
0.854 \\
0.844 \\
0.842\end{array}$ & 0.777 & 0.702 \\
\hline
\end{tabular}

Table 2. Pearson Correlations and AVE Table for Discriminant Validity

\begin{tabular}{|c|c|c|c|c|c|c|c|}
\hline & $\begin{array}{c}\text { No of original } \\
\text { scale items }\end{array}$ & Alpha & $\mathbf{1}$ & $\mathbf{2}$ & $\mathbf{3}$ & $\mathbf{4}$ & $\mathbf{5}$ \\
\hline Content (1) & 4 & 0.87 & $\mathbf{0 . 8 8}$ & & & & \\
\hline Accuracy (2) & 2 & 0.80 & 0.76 & $\mathbf{0 . 7 8}$ & & & \\
\hline Format (3) & 2 & 0.78 & 0.65 & 0.65 & $\mathbf{0 . 8 5}$ & & \\
\hline Ease of Use (4) & 2 & 0.77 & 0.68 & 0.73 & 0.77 & $\mathbf{0 . 8 3}$ & \\
\hline Timeliness (5) & 2 & 0.83 & 0.76 & 0.69 & 0.69 & 0.74 & $\mathbf{0 . 8 9}$ \\
\hline
\end{tabular}

\section{Measurement model}

Research in social sciences has been used statistical analysis for over a century. The decision-making through statistical methods has grown dramatically with the help of computer capabilities. The use of technology and user-friendly is one of the main reasons why access to statistical analysis has been widely 
practiced over recent years. In understanding data relationships, researchers must rely on univariate and bivariate analysis through advanced multivariate data analysis methods such as Structural Equation Modeling. Structural Equation Modeling or SEM is also a second generation statistical analysis technique developed for analyzing the association between multiple variables within a model framework. The relationship between variables can be expressed in a series of single or multiple regression equations. SEM techniques use quantitative combinations and correlation or causal assumptions into the model (Zainudin ,2012; Shipley ,2016; Lachowicz et al., 2018; Ning et al., 2019). SEM also can indirectly evaluate items under the latent construction individually. The latent construct is a variable that cannot be measured directly because it is just a concept of research hypothesized. Latent constructs are also known as variables that cannot be directly assessed or measured using a set of items in the questionnaire. The use of SEM can also model an association between constructions and simultaneously analyzed.

\section{RESULTS}

\section{General Characteristics of Subjects}

The study population included 88 males $(32.23 \%)$ and 185 females $(67.76 \%)$, with a mean age of $35.91 \pm$ 16.60 years. Of them, 202 individuals $(66.0 \%)$ were married, $92(30.1 \%)$ were unmarried, and $12(3.9 \%)$ were widowed or divorced. Additionally, 260 (84.9\%) were employed and $46(15.1 \%)$ were unemployed.

\section{Validity Analysis}

\section{Content Validity}

Almost all items (25/27) showed an item-level content validity index ranging between 0.80 and 1.00 and the scale-level content validity index/AVE of 0.90 , indicating adequate content validity.

\section{Item Analysis}

We analyzed the skewness and kurtosis to discover the normality of the data used in this study. The skewness of all measured variables was between 0.01-1.15 (absolute value) and did not exceed 3; kurtosis did not exceed 10 and had absolute values between $0.04-1.41$. The data presented normal distribution. However, the multivariate normality test showed that the multivariate kurtosis was 43.5 and the critical ratio was 14.2. It is not concrete to approve the combined frequency distributions for all variables, and few data justify the assumption of multivariate normality. Therefore, if there is no major problem with a univariate normality test, it can be assumed that multivariate normality is satisfied (Collier ,2020). In summary, the measured variables in this study justified univariate normality, and thus, the validity of the TASKA service quality was satisfactory.

\section{FINDINGS AND ANALYSIS}

According to Maydeu-Olivares et al. (2019), the load factor for the newly developed scale must be exceeding 0.5. In this study, all items with lower factor loading values of 0.5 are eliminated from 'construction' to ensure unidimensionality, parsimonious, incremental and absolute fit can be achieved. Analysis shows that 43 items were removed because they had a factor loading which less than 0.5. Through observation of the researchers, the item is not too weak but has a modest factor loading of between $0.3-0.49$.

Table 3. The Latent Constructs Fitness Summary

\begin{tabular}{|c|c|c|c|c|c|c|c|}
\hline Construct & & & & Incremental & & Parsimonious & Absolute \\
\hline & Chisq & Df & P value & TLI & CFI & Chisq / df & RMSEA \\
\hline
\end{tabular}


Application of Structural Equation Modeling (SEM) in Estimating the Contributing Factors to Satisfaction of TASKA Services in East Coast Malaysia

\begin{tabular}{|c|c|c|c|c|c|c|c|}
\hline Activity & 14.816 & 4 & 0.000 & 0.780 & 0.868 & 3.704 & 0.084 \\
\hline Cost & 22.986 & 5 & 0.000 & 0.766 & 0.883 & 4.797 & 0.043 \\
\hline Fees & 5.104 & 2 & 0.000 & 0.946 & 0.982 & 2,551 & 0.097 \\
\hline Manage & 8.539 & 2 & 0.000 & 0.848 & 0.949 & 4.270 & 0.021 \\
\hline
\end{tabular}

Table 3 above shows the fitness indices of all latent constructs in the model. Constructive mediators such as facilities, safety, cleanliness and reason have a value of ChiSq / $\mathrm{df}$ which is less than 5.0, so the benefits of parsimonious fitness test have been achieved for the mediators. This construct model also has TLI and CFI values higher than 0.7 and RMSEA values less than 0.10 . Therefore, additional and absolute fitness has also been achieved.

All constructs have correlations of more than 0.70 . It can be decided that discriminant validity had been accomplished and no finalized construct need to be terminated from the model. It can be concluded that all four fitness are required in this modeling had been achieved. The ChiSquare / df and RMSEA value indicate in this model was achieved a goodness of fit since the ChiSquare / df value is 3.582 which is lower than 5.0 and RMSEA value is 0.070 which is below than 0.10 (Table 4 and Figure 1).

Table 4. Model of Fitness

\begin{tabular}{|c|c|c|c|c|c|c|}
\hline Model & CMIN & DF & CMIN / DF & CFI & TLI & RMSEA \\
\hline Default model & 3230.541 & 902 & 3.582 & 0.822 & 0.845 & 0.070 \\
\hline
\end{tabular}

\section{CONCLUSION AND DISCUSSION}

Based on the results obtained through the path analysis approach and measurement model, more interesting results can be seen from the goodness of fit results that meet the mediating requirements with the help of the CFI and TLI indices, as well as the significant values of the RMSEA precision level. Parents/guardians found that the level of TASKA service satisfaction in terms of facilities was depend on the activities of children in TASKA (F1), dressing room (F3), playroom (F6), sleeping space (F7), breastfeeding space (F8) and isolation space for the purpose of contagious disease to quarantine (F9). Parents/guardians also emphasize manage matters throughout their children at TASKA (Jamaludin, H., \& Mohamad, B., 2018). Among the factors determining their level of satisfaction are the preparedness of the achievable first aid kit by TASKA (S10), the existence of barrier doors that restrict children to the kitchen (S12), outdoor playground (S14) and outdoor games (S16) (Ahmetoğlu \& Acar, 2017). In addition, the hygiene aspect is the main reason for the selection of the TASKA from the perspective of parents/guardians. The reasons are cleanliness activity around TASKA before operation time (C1), physical environment $(\mathrm{C} 2)$, sensitivity to TASKA $(\mathrm{C} 4)$ children and physical hygiene practices applied by TASKA (C5) personnel. Parents/guardians have a special reason in the selection of a TASKA (Parkes et al., 2016). The main factor that motivates the selection of TASKA is depend on TASKA distance from home, medium of language used, fees charged, curriculum provided and the age of their children (Hu et al., 2018). A significant satisfaction level for this parent/guardian can also be seen directly or indirectly (Wang et al., 2004). Furthermore to TASKA selection factors, fee indications are also a cause for the convenience offered by a TASKA (McNaughton ,1994). The fees charged also reflect the facilities provided (Rusbult et al., 1998). The significant direct and indirect impact illustrates the level of service satisfaction offered as a whole. This level of satisfaction is also indirectly influenced by the level of education and the parents/guardians occupation where the dependence of these significant decisions is assisted by three mediators; facilities, cleanliness and security. In conclusion, the combination of these five mediators constitutes a strong consumer satisfaction (parent/guardian) to approximate a complete structured equation model while supported by demographic factors such as education level, occupation, location, distance, agency, fees and age of children to strengthen the TASKA leverage factor. 


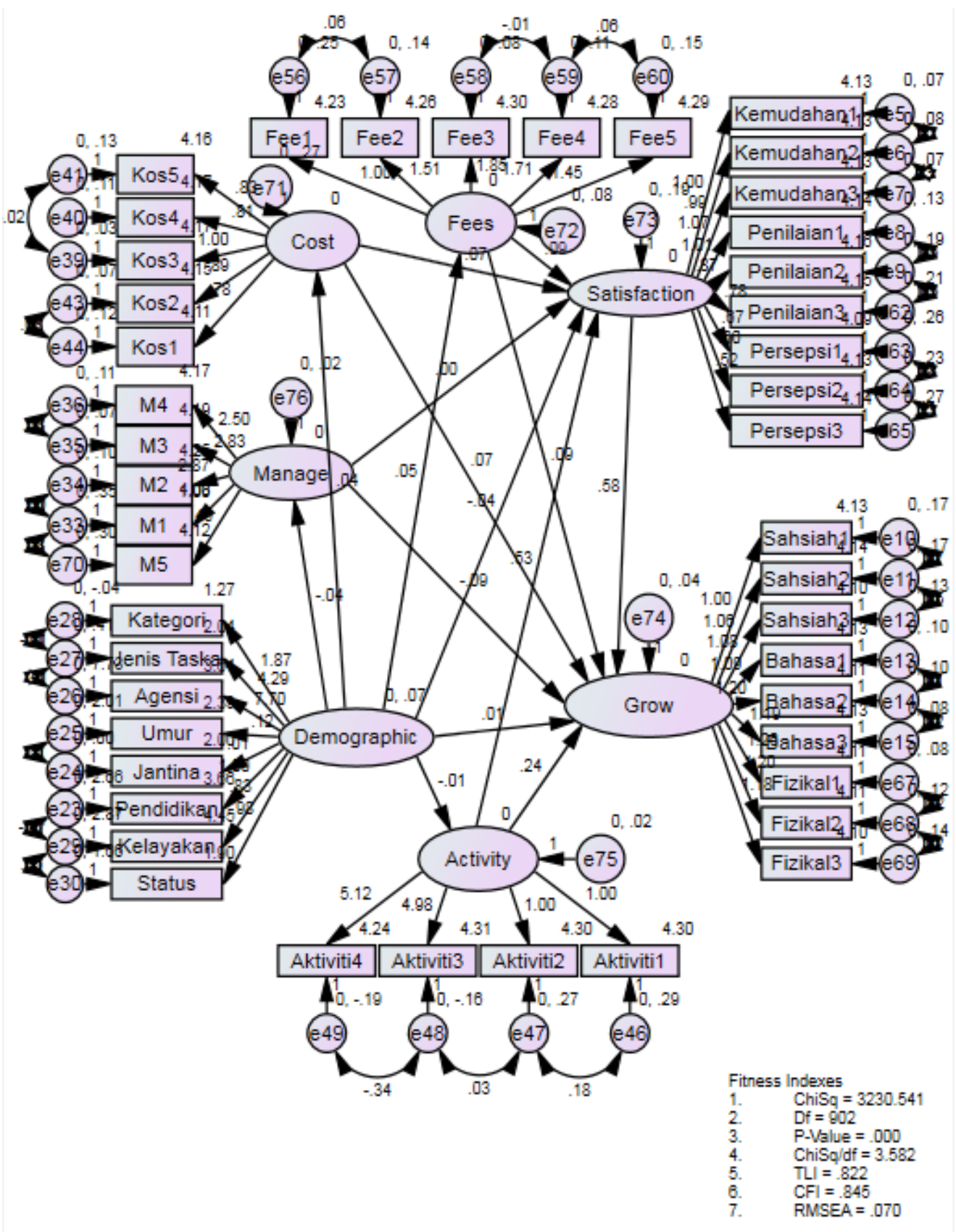

Figure 1. Measurement Model

\section{ACKNOWLEDGEMENT}

The authors thanked for the remarks and ideas received from the editor in the making of this article were completely ready for publication.

\section{REFERENCES}

Ahmetoğlu, E., \& Acar, İ. H. (2017). Parents'satisfaction With Their Children's Educational Experiences In Early Childhood Period. Electronic Turkish Studies, 12(6).

Austin, P. C., Lee, D. S., \& Leckie, G. (2020). Comparing a multivariate response Bayesian random effects logistic regression model with a latent variable item response theory model for provider profiling on multiple binary indicators simultaneously. Statistics in Medicine. 


\section{Application of Structural Equation Modeling (SEM) in Estimating the Contributing Factors to Satisfaction of TASKA Services in East Coast Malaysia}

Berti, S., Cigala, A., \& Sharmahd, N. (2019). Early Childhood Education and Care Physical Environment and Child Development: State of the art and Reflections on Future Orientations and Methodologies. Educational Psychology Review, 1-31.

Berti, S., Cigala, A., \& Sharmahd, N. (2019). Early Childhood Education and Care Physical Environment and Child Development: State of the art and Reflections on Future Orientations and Methodologies. Educational Psychology Review, 1-31.

Bertrand, J., Butler, E., Fesseha, E., Maich, K., McCuaig, K., McLean, C., ... \& Gabrielle, Y. (2019, January). Quality Early Childhood Education the Need for Special Education Services: A Symposium. In 2019 Conference of the Canadian Society for the Study of Education.

Briere, J., Runtz, M., Eadie, E., Bigras, N., \& Godbout, N. (2017). Disengaged parenting: Structural equation modeling with child abuse, insecure attachment, and adult symptomatology. Child Abuse \& Neglect, 67, $260-270$

Byrne B.M. (2013) Structural equation modeling with AMOS: basic concepts, applications, and programming. Routledge, New York

Capmourteres V, Anand M (2016) Assessing ecological integrity: a multi-scale structural and functional approach using structural equation modeling. Ecol Indic http://dx.doi.org/10.1016/j.ecolind.2016.07.006

Cava-Tadik, Y., Brown, G. L., \& Mangelsdorf, S. C. (2020). Fathers' Satisfaction With Physical Affection Before and After the Birth of a New Baby: Cross-Parent Effects and Associations With Family Dynamics. Journal of Family Issues, 41(4), 415-436.

Collier, J. E. (2020). Applied Structural Equation Modeling using AMOS: Basic to Advanced Techniques.

Garn, A. C., \& Webster, E. K. (2018). Reexamining the factor structure of the test of gross motor developmentSecond edition: Application of exploratory structural equation modeling. Measurement in Physical Education and Exercise Science, 22(3), 200-212.

Godbout, N., Daspe, M. Ė., Runtz, M., Cyr, G., \& Briere, J. (2019). Childhood maltreatment, attachment, and borderline personality-related symptoms: Gender-specific structural equation models. Psychological trauma: theory, research, practice, and policy, 11(1), 90.

Hajizadeh, A., \& Zali, M. (2016). Prior knowledge, cognitive characteristics and opportunity recognition. International Journal of Entrepreneurial Behavior \& Research.

Hoyle RH (2011) Structural equation modeling for social and personality psychology. Sage, London

Hu, B. Y., Yang, Y., Wu, H., Song, Z., \& Neitzel, J. (2018). Structural and process predictors of Chinese parental satisfaction toward early childhood education services. Children and Youth Services Review, 89, 179-187.

Jacobucci, R., Grimm, K. J., \& McArdle, J. J. (2017). A comparison of methods for uncovering sample heterogeneity: Structural equation model trees and finite mixture models. Structural equation modeling: $a$ multidisciplinary journal, 24(2), 270-282.

Jamaludin, H., \& Mohamad, B. (2018). The Relationship between Service Quality and Parent Satisfaction in Early Childhood Education: A Study among Malaysian Government Servants at Putra Jaya. Global Business and Management Research, 10(3), 486.

Kline RB (2006) Reverse arrow dynamics. Formative measurement and feedback loops. In: Hancock GR, Mueller RO (eds) Structural equation modeling: A second course. Information Age Publishing, Greenwich

Lachowicz, M. J., Preacher, K. J., \& Kelley, K. (2018). A novel measure of effect size for mediation analysis. Psychological Methods, 23(2), 244.

Maydeu-Olivares, A., Shi, D., \& Fairchild, A. J. (2019). Estimating causal effects in linear regression models with observational data: The instrumental variables regression model. Psychological methods.

McNaughton, D. (1994). Measuring parent satisfaction with early childhood intervention programs. Topics in Early Childhood Special Education, 14(1), 26-48.

Mohajan, H. K. (2017). Two criteria for good measurements in research: Validity and reliability. Annals of Spiru Haret University. Economic Series, 17(4), 59-82.

Ning, B., Ghosal, S., \& Thomas, J. (2019). Bayesian method for causal inference in spatially-correlated multivariate time series. Bayesian Analysis, 14(1), 1-28.

Papadaki, D., Bakas, D. N., Karamitsos, D., \& Kirkham, D. (2019). Big data from social media and scientific literature databases reveals relationships among risk management, project management and project success. Project Management and Project Success (September 26, 2019).

Parkes, A., Sweeting, H., \& Wight, D. (2016). What shapes 7-year-olds' subjective well-being? Prospective analysis of early childhood and parenting using the Growing Up in Scotland study. Social psychiatry and psychiatric epidemiology, 51(10), 1417-1428.

Rentzou, K. (2017). Using rating scales to evaluate quality early childhood education and care: reliability issues. European Early Childhood Education Research Journal, 25(5)

Rusbult, C. E., Martz, J. M., \& Agnew, C. R. (1998). The investment model scale: Measuring commitment level, satisfaction level, quality of alternatives, and investment size. Personal relationships, 5(4), 357-387. 
Scheiner, C. W., Baccarella, C. V., Feller, N., Voigt, K. I., \& Bessant, J. (2016). Organisational and individual unlearning in identification and evaluation of technologies. International Journal of Innovation Management, 20(02), 1650017.

Shao Y, Bao W, Chen D, Eisenhauer N, Zhang W, Pang X, Xu G, Fu S (2015) Using structural equation modeling to test established theory and develop novel hypotheses for the structuring forces in soil food webs. Pedobiologia 58(4):137-145

Shipley, B. (2016). Cause and correlation in biology: a user's guide to path analysis, structural equations and causal inference with $R$. Cambridge University Press.

Silver, R. B., Newland, R. P., Hartz, K., Jandasek, B., Godoy, L., Lingras, K. A., ... \& Seifer, R. (2017). Integrating early childhood screening in pediatrics: A longitudinal qualitative study of barriers and facilitators. Clinical Practice in Pediatric Psychology, 5(4), 426.

Wang, M., Turnbull, A. P., Summers, J. A., Little, T. D., Poston, D. J., Mannan, H., \& Turnbull, R. (2004). Severity of disability and income as predictors of parents' satisfaction with their family quality of life during early childhood years. Research and Practice for Persons with Severe Disabilities, 29(2), 82-94.

Zainudin, A. (2012). Research Methodology and Data Analysis 5th Edition. Shah Alam: Universiti Teknologi MARA Publication Center (UiTM Press). 